\title{
REGIONAL ONTOGENY OF A UNIQUE GLUTAMATE RECOGNITION SITE IN RAT BRAIN: AN AUTORADIOGRAPHIC STUDY
}

\section{J. Timothy Greenamyre, ${ }^{*}$ Donald S. Higgins, $\dagger$ Anne B. Young $\dagger$ and John B. Penney $\dagger$}

\author{
*Departments of Neurology, Neurobiology and Anatomy, and Pharmacology, University of Rochester Medical Center, \\ Rochester, NY 14642, U.S.A.
}

†Department of Neurology, University of Michigan, Neuroscience Lab. Bldg, Ann Arbor, M1 48104-1687, U.S.A.

(Received 14 August 1989; in final revised form 14 March 1990; accepted 3 April 1990)

\begin{abstract}
The developmental pattern of $L-\left[{ }^{3} \mathrm{H}\right]$ glutamate binding to rat brain in the presence of saturating concentrations of unlabeled $\mathrm{N}$-methyl-D-aspartate (NMDA), kainate (KA) and quisqualate (QQA) was examined in an autoradiographic assay. The unique glutamate binding site defined by this assay displayed four distinct, regionally specific patterns of development. (1) In reticular nucleus of thalamus there was an initial very high level of binding at postnatal day 1 (PND1) followed by a progressive $80 \%$ decline in binding during maturation. (2) In entorhinal cortex, a progressive $500-1100 \%$ increase in binding was seen during development. (3) In ventral posterior medial nucleus of thalamus, there was an initial transient $200-300 \%$ increase in binding, peaking at PND10, followed by a steady decline in binding. (4) In frontal cortex, binding remained relatively stable throughout development. At all stages of development, the distribution of these recognition sites was different from NMDA, KA or $\mathrm{QQA}$ receptors. The function of this glutamate binding site remains to be determined, but the distinct regional and temporal patterns of binding suggest that it may be important in normal development of the central nervous system.
\end{abstract}

Key words: development, glutamate binding, kainate, N-methyl-D-aspartate, quisqualate, reticular nucleus.

The effects of excitatory amino acids are mediated by a variety of different receptor types. At least five distinct receptors have been identified and partially characterized. There are receptors named for kainate (KA), quisqualate (QQA) and N-methyl-D-aspartate (NMDA), each of which appears to be associated with an ion channel. ${ }^{6,24}$ There is also a metabotropic receptor which is linked to phosphoinositol metabolism. ${ }^{16,21}$ Finally, electrophysiological studies have demonstrated a receptor at which 2-amino-4-phosphonobutyrate (APB) is an antagonist. ${ }^{4}$

There may also be other excitatory amino acid receptor types which have not yet been characterized. For example, glutamate still has excitatory electrophysiological actions in the presence of antagonists in concentrations sufficient to block both NMDA and KA/QQA responses. ${ }^{10}$ Little is known about the developmental profile or function of these NMDA-, KA-, QQA-insensitive excitatory glutamate receptors.

We have recently characterized a unique neuronal glutamate recognition site in rat brain that is distinct from any known receptor type. ${ }^{9}$ This site was assayed in the presence of saturating concentrations of NMDA, QQA and KA, and binding was dependent upon chloride ions and enhanced by calcium ions. This site may correspond to the calcium- and chloride-dependent site first described by Monaghan et al. ${ }^{13}$

This unique non-NMDA, non-KA, non-QQA (NNKQ) site is expressed transiently in the globus pallidus during development of human and rat brain. ${ }^{7}$ Although assay conditions were different in the original report describing this transient glutamatergic innervation of globus pallidus, reanalysis of our binding data and subsequent experiments have confirmed that the NNKQ comprised more than $50 \%$ of the binding we measured. In the globus pallidus, expression of this site correlated well with other biochemical measures of glutamatergic innervation during development. ${ }^{7}$

"Address correspondence to: J. T. Greenamyre, Department of Neurology, University of Rochester Medical Center, 601 Elmwood Avenue, Box 673, Rochester, NY 14642, U.S.A.

Abbreviations: $\mathrm{APB}, 2$-amino-4-phosphonbutyrate; $\mathrm{Cb}-\mathrm{G}$, cerebellar granule cell layer; $\mathrm{Cb}-\mathrm{M}$, cerebellar molecular layer; $C G$, central gray; DG, dentate gyrus; $D L G$, dorsal lateral geniculate; Ent, entorhinal cortex; Fr, frontal cortex, IC, inferior colliculus; KA, kainate; MG, medial geniculate; NMDA, N-methyl-D-aspartate; NNKQ, non-NMDA, non-KA, non-QQA glutamate binding site; PND, postnatal day; QQA, quisqualate; Rt, reticular nucleus of thalamus; SITS, 4-acetamido-4'-isothiocyanostilbene-2, $2^{\prime}$ - disulfonic acid; SLM, stratum lacunosum moleculare; Str, striatum; VPM,
ventral posterior medial nucleus of thalamus. 
Using an autoradiographic assay specific for the NNKQ site, we now describe in detail the regional ontogeny of this unique glutamate recognition site.

\section{EXPERIMENTAL PROCEDURES}

\section{Materials}

$\mathrm{L}-\left[{ }^{3} \mathrm{H}\right]$ Glutamate was obtained from Amersham (Arlington Heights, IL). NMDA and quisqualate were obtained from Cambridge Research Biochemicals (Valley Stream, NY). All other chemicals were obtained from Sigma (St. Louis, MO).

\section{Tissue preparation}

Sprague-Dawley rats at ages PND1, PND4, PND7, PND10, PND14, PND21, PND28 and adult were decapitated, and their brains were quickly removed and frozen under powdered dry ice $(n=4$ at each age, except PND21, where $n=3$ ). Twenty $\mu \mathrm{m}$ sections were cut on a Lipshaw cryostat and thaw-mounted onto gelatin-coated slides, then allowed to dry at room temperature. Sections were stored at $-20^{\circ} \mathrm{C}$ and used for assay within $24 \mathrm{hr}$. Prior to assay, sections were prewashed for $30 \mathrm{~min}$ at $2^{\circ} \mathrm{C}$ in $50 \mathrm{mM}$ Tris- $\mathrm{HCl}(\mathrm{pH} \mathrm{7.4)}$ in order to remove free endogenous excitatory amino acids. This procedure does not completely remove excitatory amino acids, but harsher treatments damage the mounted tissue. After the pre-wash, sections were blown dry under a stream of room temperature air.

\section{Autoradiography}

$\mathrm{L}-\left[{ }^{3} \mathrm{H}\right]$ Glutamate binding was assayed by incubating tissue sections for $45 \mathrm{~min}$ at $2^{\circ} \mathrm{C}$ in $50 \mathrm{mM}$ Tris- $\mathrm{HCl}$ buffer containing $2.5 \mathrm{mM} \mathrm{CaCl}_{2}$, in the presence of $900 \mu \mathrm{M} \mathrm{NMDA}, 2.25 \mu \mathrm{M}$ QQA and $900 \mathrm{nM}$ KA. In saturation studies, concentrations of $\mathrm{L}-\left[{ }^{3} \mathrm{H}\right]$ glutamate ranged between $80 \mathrm{nM}$ and $7 \mu \mathrm{M}$. For regional distribution studies, the final concentration of $\mathrm{L}-\left[{ }^{3} \mathrm{H}\right] \mathrm{glutamate}$ (sp. act. $21 \mathrm{Ci} /$ $\mathrm{mmol}$ ) was $72 \mathrm{nM}$. Nonspecific binding was defined by $1 \mathrm{mM}$ unlabeled glutamate. The slides were removed from the ligand solution and rinsed 3 times with ice-cold buffer, and then rinsed with cold $2.5 \%(\mathrm{v} / \mathrm{v})$ glutaraldehyde in acetone. Slides were blown dry with warm air. The rinse and drying procedure took no more than $10 \mathrm{sec}$. Dried slide-mounted sections were placed in $\mathrm{X}$-ray cassettes with appropriate radioactive standards and apposed to Hyperfilm (Amersham). The film was exposed to the tissue sections for 21 days at $4^{\circ} \mathrm{C}$ and then developed, fixed and dried. Autoradiograms were analysed using an MCID image processing system (Imaging Research, Inc., St. Catharine's, Ontario, Canada). All data presented were analysed from autoradiographic images.

\section{RESULTS}

\section{Characterization of the $N N K Q$ site}

Binding experiments were carried out under conditions in which there was negligible, if any, binding to NMDA, kainate or quisqualate receptors. In this assay, the NNKQ site was defined as glutamate binding in the presence of saturating concentrations of NMDA, kainate and quisqualate. This site had a $K_{\mathrm{D}}$ of about $1 \mu \mathrm{m}$, determined by both Scatchard and kinetic analysis, and a Hill coefficient close to unity. Binding was unaffected by a variety of glutamate agonists or antagonists, or by the anion channel blocker 4-acetamido-4'-isothiocyanostilbene-2,2'-disulfonic acid (SITS). Binding in striatum was unaffected by ipsilateral decortication, but was reduced by $65 \%$ in striatal quinolinate lesions, strongly suggesting a neuronal localization. ${ }^{9}$

Binding to the NNKQ site was saturable and in layers 1 and 2 of entorhinal cortex of adult animals, Scatchard analysis yielded a linear plot with a $K_{\mathrm{D}}$ of $1.03 \pm 0.20 \mu \mathrm{M}$ and a $B_{\max }$ of $3.03 \pm 0.12 \mathrm{pmol} / \mathrm{mg}$ protein (Fig. 1). Scatchard analyses in other brain regions gave similar affinities, indicating that regional differences in residual endogenous glutamate levels were not affecting binding. A detailed description of the characteristics of the NNKQ site is in preparation ${ }^{9}$ (Higgins et al., in preparation).

The NNKQ site had a regional distribution in adult rats that was distinct from NMDA, KA and QQA receptors. ${ }^{8,15}$ At a $\mathrm{L}-\left[{ }^{3} \mathrm{H}\right]$ glutamate concentration of $72 \mathrm{nM}$, highest levels of binding were 


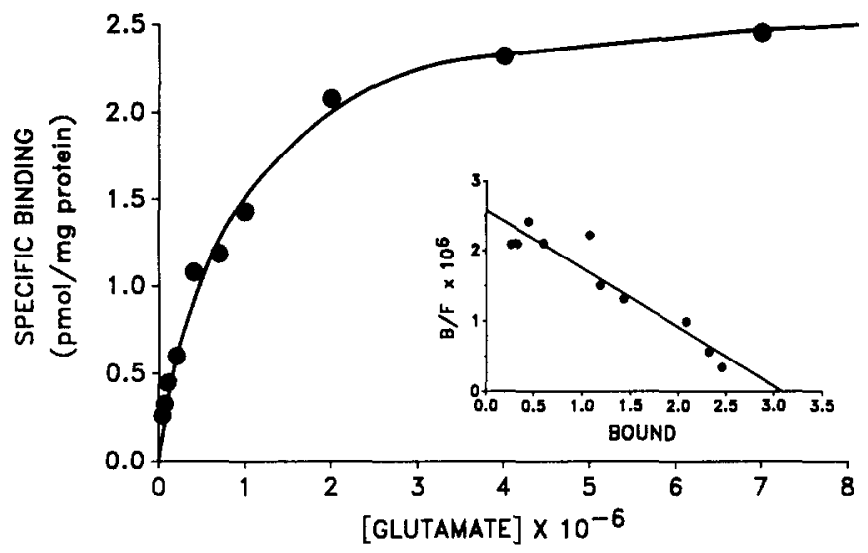

Fig. 1. Representative saturation and Scatchard plots of $L-\left[{ }^{3} \mathrm{H}\right]$ glutamate binding to laminae 1 and 2 of entorhinal cortex in adult rats. Binding was performed in the presence of saturating concentrations of NMDA, KA and QQA. Each point represents specific binding. The experiment has been repeated three times in three separate animals with similar results.

found in superficial layers of frontal cortex $(1.94 \pm 0.07 \mathrm{pmol} / \mathrm{mg}$ protein), medial striatum $(1.21 \pm 0.10 \mathrm{pmol} / \mathrm{mg}$ protein) and dentate gyrus $(0.81 \pm 0.04 \mathrm{pmol} / \mathrm{mg}$ protein $)$. Moderate binding was seen in stratum radiatum of CA1 $(0.44 \pm 0.01 \mathrm{pmol} / \mathrm{mg}$ protein) and very low levels of binding were seen in globus pallidus $(0.08 \pm 0.01 \mathrm{pmol} / \mathrm{mg}$ protein $)$.

\section{Ontogeny of the $N N K Q$ site}

Thalamus. At PND1, the level of binding to the NNKQ site was low to moderate throughout the brain, except in the reticular nucleus of the thalamus. In this region, the level of binding at $72 \mathrm{nM} \mathrm{L}-\left[{ }^{3} \mathrm{H}\right]$ glutamate $(2.37 \pm 0.17 \mathrm{pmol} / \mathrm{mg}$ protein) was almost 20 -fold higher than that in the superficial entorhinal cortex $(0.12 \pm 0.02 \mathrm{pmol} / \mathrm{mg}$ protein), and was more than twice as high as any other structure in the forebrain, cerebellum or brainstem (Figs 2 and 3). After PND4, there was a progressive decline in binding in the reticular nucleus, and by adulthood the level of binding was only $23 \%$ of that at PND1. A different developmental pattern of binding was seen in other thalamic nuclei including ventral posterior medial (VPM), dorsal lateral geniculate (DLG) and medial geniculate (MG). In these structures, there was a progessive $200-300 \%$ increase in binding which was maximal at PND10, and a subsequent progressive decline in binding to adult levels (Figs 2 and 3 ).

Cerebral cortex. In the frontal cortex, binding increased slightly between PND1 and PND4 and remained essentially stable thereafter into adulthood (Figs 2 and 3). There was a laminar pattern of binding with layers 1,2 and 4 having higher levels of binding than layers 3,5 and 6 . In contrast to the frontal cortex, binding in the entorhinal cortex increased progessively between PND1 $(0.12 \pm 0.02 \mathrm{pmol} / \mathrm{mg}$ protein) and adulthood $(1.35 \pm 0.08 \mathrm{pmol} / \mathrm{mg}$ protein $)$. A clear demarcation between parietal cortex and entorhinal cortex was apparent in adult animals. From the midportion of parietal cortex, extending posteriorly, there was a progressive decrease in binding until entorhinal cortex began, at which point there was an abrupt increase in binding (Fig. 2).

Hippocampus. Throughout development, there was little NNKQ binding in stratum radiatum or stratum oriens in any of the hippocampal subfields, nor was there much binding in stratum lucidum. Binding in stratum lacunosum moleculare was higher than background hippocampal binding by PND4 and this region continued to have the highest level of binding in hippocampus until PND14, when high levels of binding to the stratum moleculare of dentate gyrus became apparent. In adult animals, this region of brain had one of the highest levels of binding.

Other regions. In the striatum, there was an increase in glutamate binding between PND1 and PND4 and then glutamate binding remained relatively stable until adulthood. As noted previously, there was a transient peak of glutamate binding in the globus pallidus at PND7. ${ }^{7}$ Binding in cerebellar cortex remained relatively stable throughout development despite the morphological changes that occur in this structure during maturation. In the inferior colliculus, binding increased between PND1 and PND10 and then decreased to adult levels. This is the same 


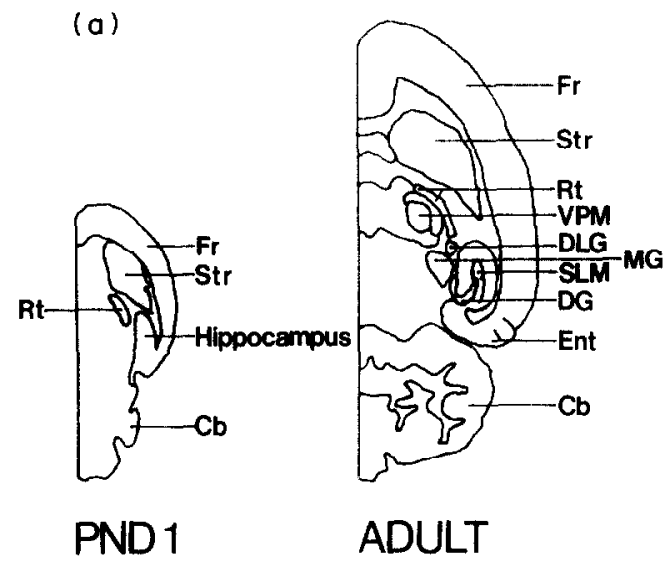

Fig. 2. Autoradiographs of $L-\left[{ }^{3} \mathrm{H}\right]$ glutamate binding to the NNKQ site during development. (a) Schematic drawing representing sections from PND1 adult brain. (b) Color transformation of $\left[{ }^{3} \mathrm{H}\right]$ glutamate binding to the NNKQ site. Each image shows binding to one-half of a horizontal scction of rat brain. All sections were assayed simultaneously in the same ligand solution and placed on the same piece of tritium-sensitive film. Autoradiographic images were analysed identically so that direct comparison of levels of binding can be made between sections. The color bar provides a direct indication of the level of binding. The schematic diagram shows PND1 and adult brains with selected regions labeled. Fr, frontal cortex; Str, striatum; Rt, reticular nucleus; VFM, ventral posterior medial nucleus; DLG, dorsal lateral geniculate; MG, medial geniculate; SLM, stratum lacunosum moleculare; DG, dentate gyrus; Ent, entorhinal cortex; $\mathrm{Cb}$, cerebellum.

pattern of binding that was seen in several thalamic nuclei (VPM, DLG and MG). In the periaqueductal central gray region, binding remained relatively stable from PND1 to PND14 and thereafter decreased by about $70 \%$ to adult levels.

\section{DISCUSSION}

The NNKQ glutamate binding site was defined by its insensitivity to saturating concentrations of NMDA, KA and QQA. Of note, previous studies have shown binding to this site was also unaffected by APB or SITS. ${ }^{9}$ Binding to the NNKQ site was saturable and rapidly reversible with a $t_{1 / 2}$ of $24 \mathrm{sec}$. It was apparently associated with neurons but not glia or glutamatergic afferent terminals based on lesion studies. ${ }^{9}$ The function of this glutamate recognition site is unknown, and whether it represents another type of excitatory amino acid receptor is unclear. Honore et al. ${ }^{10}$ have shown that glutamate can still exert excitatory electrophysiological effects in the presence of saturating concentrations of both NMDA and QQA/KA antagonists. Thus, it is possible that there is another, as yet undefined, glutamate receptor that is insensitive to NMDA, KA or QQA antagonists, and it is tempting to speculate that the NNKQ glutamate binding site could represent such a receptor. Pharmacological studies of this NMDA/QQA/KA-insensitive glutamatergic electrophysiological effect will be necessary to confirm this possibility.

It is unlikely that the NNKQ site is a transport site. In striatum, lesion studies indicated that binding was associated with intrinsic neurons and not with afferent glutamatergic nerve terminals or glia. In contrast to other known uptake sites, ${ }^{1,11,20,23}$ NNKQ binding was not sodium-dependent and was not inhibited by cystine, threo-hydroxyasparate, D-aspartate, dihydrokainate or SITS. ${ }^{9}$

A variety of glutamate binding sites are chloride-dependent and enhanced by $\mathrm{Ca}^{2+}$ (for discussion, see Ref. 5). The NNKQ site is distinct from each of these sites. Glutamate binding to the QQA receptor is chloride/calcium-dependent but, in contrast to the NNKQ site, is displaced by very low concentrations of QQA $\left(K_{\mathrm{I}} \approx 20 \mathrm{nM}\right){ }^{5,8}$ Unlike APB-sensitive, chloride-dependent glutamate sequestration, ${ }^{14,18}$ binding was maximal at $2^{\circ} \mathrm{C}$ and was unaffected by APB. Finally, the low-affinity glial glutamate uptake site is chloride-dependent, ${ }^{23}$ but the NNKQ site appears to be localized on neurons and is not displaced by SITS.

\section{Regional ontogeny}

Four distinct, regionally specific patterns of development were seen in NNKQ binding. First, in the reticular nucleus of thalamus, levels of binding were extremely high relative to other regions at 


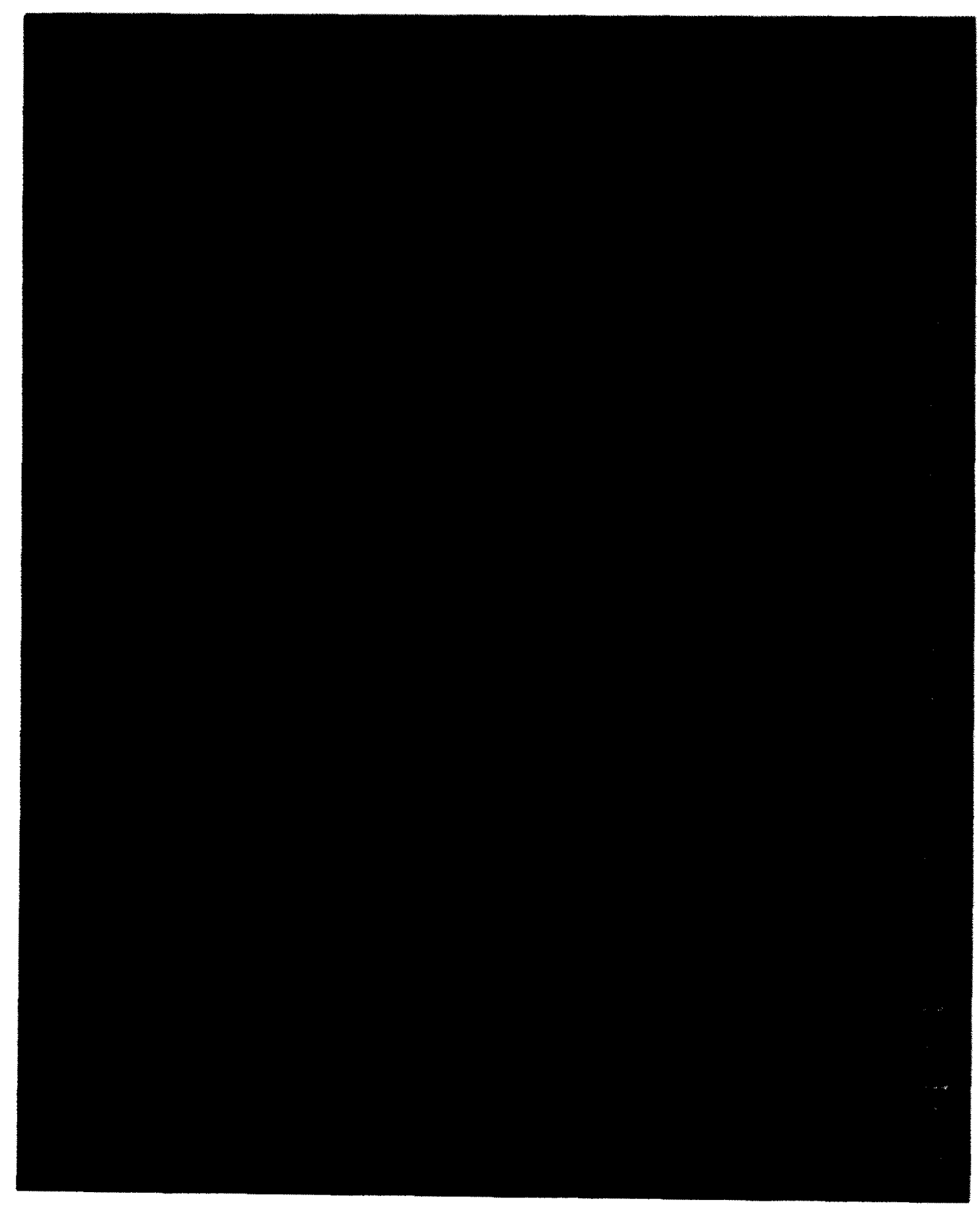

Fig. 2(b). 


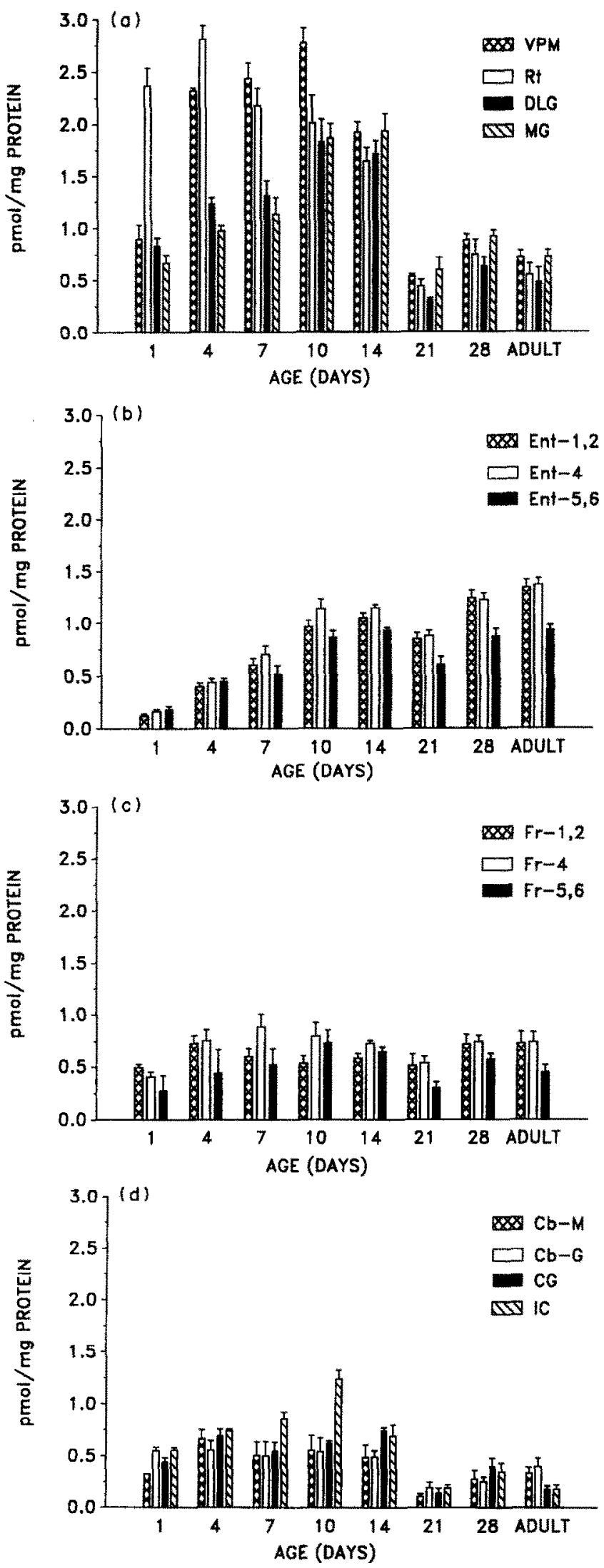

Fig. 3. Histograms of $L-\left[{ }^{3} \mathrm{H}\right]$ glutamate binding to the NNKQ site. The concentration of $\mathrm{L}-\left[{ }^{3} \mathrm{H}\right]$ glutamate was 72 nM. Values represent mean \pm S.E.M. $(n=4$ animals at each age except PND21, where $n=3)$. NNKQ binding sites in thalamic nuclei are shown in (a); binding in entorhinal cortex in (b); frontal cortex in (c); and cerebellum and brainstem in (d). VPM, ventral posterior medial nucleus; Rt, reticular nucleus; DLG, dorsal lateral geniculate; $\mathrm{MG}$, medial geniculate; $\mathrm{Cb}-\mathrm{M}$, cerebellar molecular layers; $\mathrm{Cb}-\mathrm{G}$, cerebellar granule layer; $\mathrm{CG}$, central gray; IC, inferior colliculus; $\mathrm{Fr}$, frontal cortex; Ent, entorhinal cortex. Numbers in (b) and (c) (e.g. Fr -1,2) refer to cortical layers according to Bayer. ${ }^{3}$ 
PND1; after PND4, there was a progessive decline in binding leading ultimately to an $80 \%$ reduction in NNKQ binding in this region. A similar high density of glutamate binding sites has been described in the reticular nucleus of thalamus in human fetal brain, ${ }^{2}$ The pharmacology of the glutamate binding site in human brain was not examined, but the assay was performed under conditions in which there was substantial binding to the NNKQ site.

A second developmental pattern of binding was seen in VPM, DLG and MG of thalamus, as well as inferior colliculus. Binding in these structures increased during the first postnatal week, peaked at PND10, and declined over a period of weeks to adult levels. The relative increase in binding between PND1 and PND10 ranged between $220 \%$ in DLG and $300 \%$ in VPM. In general, the level of binding seen in these structures at PND1 was similar to that seen in adult animals. The developmental pattern of NNKQ binding sites in these structures was remarkably similar to that of glutamate binding sites in globus pallidus described previously. ${ }^{7}$ In this earlier study, however, approximately $45 \%$ of the binding sites were sensitive to quisqualate; the remainder of the sites were insensitive to NMDA, KA or QQA. Thus, more than half of the glutamate binding seen at PND7 in globus pallidus was associated with the NNKQ site.

In the entorhinal cortex, a third developmental pattern of NNKQ binding was seen. Beginning at PND1, there was a progressive increase in glutamate binding throughout development so that by adulthood, binding had increased between $500 \%$ (layers 5 and 6 ) and $1100 \%$ (layers 1 and 2 ). In adult animals, there was a clear demarcation between binding in posterior parietal cortex and binding in entorhinal cortex. The abrupt increase in binding seen in entorhinal cortex stands in direct contrast to the abrupt decrease in NMDA receptor binding seen in this region. ${ }^{8,12,15}$

Finally, in frontal cortex, there was a fourth developmental pattern of NNKQ binding in which relatively constant levels of binding were seen throughout development. The distribution of binding in frontal cortex was distinctly laminar at all stages of development.

\section{Comparison with $N M D A, K A$ and $Q Q A$ receptors}

In general, the density of NMDA, KA and QQA receptors increases progressively during postnatal development; however, there are exceptions. It has been reported that there is a transient 'over-expression' of NMDA receptors in stratum radiatum of hippocampus during development. ${ }^{22}$ In addition, KA receptors are transiently increased above adult levels in dentate gyrus of human hippocampus during early postnatal development. ${ }^{19}$ QQA receptors show no such transient increases during development. Thus, the pattern of development of NMDA, KA and QQA receptors is quite different from that of the NNKQ site

At present, the function of the NNKQ site is unknown; however, the distinct temporal and regional patterns of binding seen during development of rat and human brain suggest that it may play specific roles in the normal maturation of the central nervous sytem. The roles of this unique glutamate recognition site in human neurological disease are being examined. ${ }^{17}$

\section{REFERENCES}

1. Balcar V. J. and Johnston G. A. R. (1972) The structural specificity of the high affinity uptake of L-glutamate and L-aspartate by rat brain slices. $J$. Neurochem. 19, 2657-2666.

2. Barks J. D., Silverstein F. S., Sims K., Greenamyre J. T. and Johnston M. V. (1988) Glutamate recognition sites in human fetal brain. Neurosci. Lett. 84, 131-136.

3. Bayer S. A. (1985) Hippocampal region. In The Rat Nervous System, Vol. 1 (ed. Paxinos G.), pp. 336-337. Academic Press, Australia.

4. Bridges R. J., Hearn T. J., Monaghan D. T. and Cotman C. W. (1986) A comparison of 2-amino-4-phosphonobutyric acid (AP4) receptors and [ $\left.{ }^{3} \mathrm{H}\right] \mathrm{AP} 4$ binding sites in rat brain. Brain Res. 375, 204-209.

5. Cha J. J., Greenamyre J. T., Nielsen E. O., Penney J. B. and Young A. B. (1988) Properties of quisqualate-sensitive L. $\left[{ }^{3}\right.$ H lglutamate binding sites as determined by quantitative autoradiography. $J$. Neurochem. $51,469-478$.

6. Dingledine R., Boland L. M., Chamberlin N. L., Kawasaki K., Kleckner N. W., Traynelis S. F. and Verdoon T. A. (1988) Amino acids receptors and uptake systems in the mammalian central nervous system. Crit. Rev. Neurobiol. 4, $1-96$.

7. Greenamyre J. T., Penney J. B., Young A. B., Hudson C., Silverstein F. S. and Johnston M. V. (1987) Evidence for transient perinatal glutamatergic innervation of globus pallidus. $J$. Neurosci. 4, 1022-1030.

8. Greenamyre J. T., Olson J. M. M., Penney J. B. and Young A. B. (1985) Autoradiographic characterization of N-methyl-D-aspartate-, quisqualate- and kainate-sensitive glutamate binding sites. J. Pharmac. exp. Ther. 233, 254-263.

9. Higgins D. S., Greenamyre J. T., Cha J. J., Penney, J. B. and Young A. B. (1989) A unique glutamate binding site in an autoradiographic assay. Soc. Neurosci. Abstr., Vol. 15. 
10. Honore T., Davies S. N., Drejer J., Fletcher E. J., Jacobson P., Lodge D. and Nielsen F. E. (1988) Quinoxalinediones: potent competitive non-NMDA glutamate receptor antagonists. Science 241, 701-703.

11. Kessler M., Baudry M., and Lynch G. (1987) Use of cystine to distinguish glutamate binding from glutamate sequestration. Neurosci. Lett. 81, 221-226.

12. Monaghan D. T. and Cotman C. W. (1985) Distribution of N-methyl-D-aspartate-sensitive L- $\left[{ }^{3} \mathrm{H}\right]$ glutamate binding sites in rat brain. J. Neurosci. 5, 2909-2919.

13. Monaghan D. T., Holets V. R., Toy D. W. and Cotman C. W. (1983) Anatomical distributions of four pharmacologically distinct ${ }^{3} \mathrm{H}-\mathrm{I}$-glutamate binding sites. Nature 306, 176-179.

14. Monaghan D. T., McMills M. C., Chamberlin A. R, and Cotman C. W. (1983) Synthesis of [ $\left.{ }^{3} H\right] 2$-amino-4-phosphonobutyric acid and characterization of its binding to rat brain membranes: a selective ligand for the chloride/ calcium-dependent class of L-glutamate binding sites. Brain Res. 278, 137-144.

15. Monaghan D. T., Yao D. and Cotman C. W. (1985) L- $\left[{ }^{3} \mathrm{H}\right]$ Glutamate binds to kainate-, NMDA- and AMPAsensitive binding sites: an autoradiographic analysis. Brain Res. 340, 378-383.

16. Nicoletti F., Iadarola M. J., Wroblewski J. T. and Costa E. (1986) Excitatory amino acid recognition sites coupled with inositol phospholipid metabolism: developmental changes and interaction with alpha 1-adrenoceptors. Proc. natn. Acad. Sci., U.S. A. 83, 1931-1935.

17. Penney J. B., Maragos W. F., Greenamyre J. T., DeBowey D. L., Hollingsworth Z. and Young A. B. (1990) Excitatory amino acid binding sites in the hippocampal region of Alzheimer's disease and other dementias. J. Neurol. Neurosurg. Psychiat., 53, 314-320.

18. Pin J. P., Bockaert J. and Recasens M. (1984) The $\mathrm{Ca}^{2+} / \mathrm{Cl}$-dependent L- $\left[{ }^{3} \mathrm{H}\right]$ glutamate binding: a new receptor or a particular transport process? FEBS Lett. 175, 31-36.

19. Represa A., Tremblay, E., Schoevart D. and Ben-Ari Y. (1986) Development of high affinity kainate binding sites in human and rat hippocampi. Brain Res. 384, 170-174.

20. Roberts P. J. and Watkins J. C. (1975) Structural requirements for the inhibition of L-glutamate uptake by glia and nerve endings. Brain Res. 85, 120-125.

21. Sladeczek F., Pin J. P., Recasens M., Bockaert J. and Weiss S. (1985) Glutamate stimulates inositol phosphate formation in striatal neurons. Nature 317, 717-719.

22. Tremblay E., Roisin M. P., Represa A., Charriaut-Marlangue C. and Ben-Ari Y. (1988) Transient increased density of NMDA binding sites in the developing rat hippocampus. Brain Res. 461, 393-396.

23. Waniewski R. A. and Martin D. L. (1984) Characterization of L-glutamic acid transport by glioma cells in culture: evidence for sodium-independent, chloride-dependent high affinity influx. J. Neurosci. 4, 2237-2246.

24. Watkins J. C. and Evans R. H. (1981) Excitatory amino acid neurotransmitters. Ann. Rev. Pharmac. Toxicol. 21, 165-204. 